\title{
O USO DO JOGO NO ENSINO DA MATEMÁTICA
}

\section{The use of the game in teaching mathematics}

\author{
Paula Menezes dos Santos- UERN/ Rio Grande do Norte - Brasil \\ Raiane Silva - UERN / Rio Grande do Norte - Brasil \\ Caio Reis - UERN / Rio Grande do Norte - Brasil
}

\begin{abstract}
RESUMO: Este artigo tem o objetivo de mostrar como o uso de jogos contribui para desenvolvimento do conhecimento matemático. Assim, foi realizada uma discussão bibliográfica e relatada a experiência de ensino de matemática considerando que atividades lúdicas pode ajudar na produção do conhecimento matemático e no desenvolvimento social do estudante. Primeiramente, iremos mostrar, com base numa pesquisa teórica, como aplicação de jogos em sala de aula contribui para o desenvolvimento do conhecimento. E depois, apresentaremos como escolher o jogo mais adequado e como aplicá-lo em sala de aula. A experiência foi feita na Escola de Ensino Fundamental Horizonte da Cidadania, localizada na cidade de Icapuí (CE), com 10 alunos do $6^{\circ}$ ano. O mesmo abordava os conteúdos radiciação e potenciação com o objetivo de ajudar os alunos a fixarem o conteúdo abordado em sala de aula. Foi proposto que os alunos se reunissem dois a dois para a realização do jogo no qual possuía regras e objetivos predeterminados. A realização do jogo motivou os alunos que mostraram interesse tirando as dúvidas que tinham sobre o conteúdo abordado, sendo possibilitou o domínio do conteúdo.
\end{abstract}

Palavras-chave: Aprendizagem; Ensino de matemática; Jogos.

ABSTRACT: This article aims to show how the use of games contributes to the development of mathematical knowledge. Thus, a bibliographical discussion was conducted and the experience of teaching mathematics was reported considering that playful activities can help in the production of mathematical knowledge and social development of the student. First, we will show, based on theoretical research, how application of classroom games contributes to the development of knowledge. And then we'll introduce you how to choose the most appropriate game and how to apply it in the classroom. The experiment was carried out at Horizonte da Cidadania Elementary School, located in the city of Icapuí (CE), with 10 students from the 6th grade. It addressed the content of root and empowerment in order to help students fix the content addressed in the classroom. It was proposed that the students meet two by two for the realization of the game in which it had predetermined rules and objectives. The realization of the game motivated the students who showed interest removing the doubts they had about the content approached, allowing the mastery of the content.

Keywords: Didactions. Mathematical knowledge. Teacher. Applications.

\section{INTRODUÇÃO}

A educação matemática surgiu no século XIX, em consequência dos primeiros questionamentos sobre o ensino de matemática. Embora a Matemática faça parte do

Educação, Psicologia e Interfaces, Volume 2, Número 3, p. 71-81, Setembro/Dezembro, 2018. 
cotidiano das pessoas, e esteja presente em quase todas as nossas ações, no ambiente escolar ela se apresenta muito desvinculada do contexto dos educandos; a disciplina se apresenta sistemática, mecânica e sua linguagem muitas vezes se diferencia da língua falada, tornando a compreensão dos seus conceitos mais difícil do que deveria ser. A partir daí foi surgindo à necessidade de mudanças no método de ensino de matemática.

O surgimento de novas concepções sobre como se dá o conhecimento, tem possibilitado outras formas de considerar o papel do jogo no ensino. O jogo, na educação matemática, passa a ter o caráter de material de ensino quando considerado "provocador" de aprendizagem. O aluno, colocado diante de situações lúdicas, apreende a estrutura lógica da brincadeira e, sendo assim, apreende também a estrutura matemática presente. O jogo será conteúdo assumido com a finalidade de desenvolver habilidades de resolução de problemas, possibilitando ao aluno a oportunidade de criar planos de ação para alcançar determinados objetivos, executar jogadas de acordo com este plano e avaliar sua eficácia nos resultados obtidos. Segundo Moura (1991), o jogo aproxima-se da matemática via desenvolvimento de habilidades de resolução de problemas, e ainda, permite trabalhar os conteúdos culturais inerentes ao próprio jogo.

Como o uso de jogos pode auxiliar no Ensino de Matemática? Das diversas formas de aprendizagem a utilização dos jogos tem sido usada como estratégia de ensinoaprendizagem em sala de aula. Ela é um recurso pedagógico que tem apresentado bons resultados, pois cria situações que permitem ao aluno desenvolver métodos para resolução de problemas, estimulando a sua criatividade e participação. Rêgo e Rêgo (2000) destacam que é crucial a introdução de novas metodologias de ensino, onde o aluno seja o sujeito da aprendizagem, respeitando o seu contexto, e levando em consideração os aspectos lúdicos e recreativos das motivações próprias da sua idade, de sua imensa curiosidade e desejo de realizar atividades em grupo.

O objetivo geral desse artigo é mostrar como o uso de jogos contribui para desenvolvimento do conhecimento matemático. Assim, foi realizada uma discussão bibliográfica e relatada a experiência de ensino de matemática considerando que atividades lúdicas pode ajudar na produção do conhecimento matemático e no desenvolvimento social do estudante.

\section{MATERIAL E MÉTODO}


Foi realizada uma experiência de ensino de matemática, com jogo na Escola de Ensino Fundamental Horizonte da Cidadania, da rede pública municipal localizada na Rua, na comunidade de Redonda da cidade de Icapuí (cidade situada na zona litorânea do estado do Ceará (CE), á aproximadamente 204 km capital Fortaleza).

Realizou-se a aplicação de jogos em sala de aula com alunos do Ensino Fundamental II, no $6^{\circ}$ ano da Escola de Ensino Fundamental Horizonte da Cidadania, da cidade de Icapuí/CE. Durante as aulas de monitoria da disciplina de Matemática foram incluídos 10 alunos.

Esta pesquisa foi realizada no período de Maio de 2016, o recurso utilizado foi a Roda da Potenciação, que tem os objetivos de reforçar os conceitos de potenciação, fixar os conteúdos expostos em sala de aula e promover o trabalho em equipe. Esse jogo é composto por roletas com potências e fichas com os resultados de cada potência. Após a escolha do jogo, foi-se ao processo de produção, para isso foram utilizados lápis hidrocor, canetas, cartolinas, tesouras e clipes, para a elaboração do material dos jogos.

Os procedimento usados para realização desse jogo incluíram formarem duplas, posteriormente foi entregue aos alunos duas rodas (Figuras 1 e 2) diferentes com suas respectivas respostas em cartões e também clipes para a fixação dos cartões (Figuras 3 e 4) nas rodas.

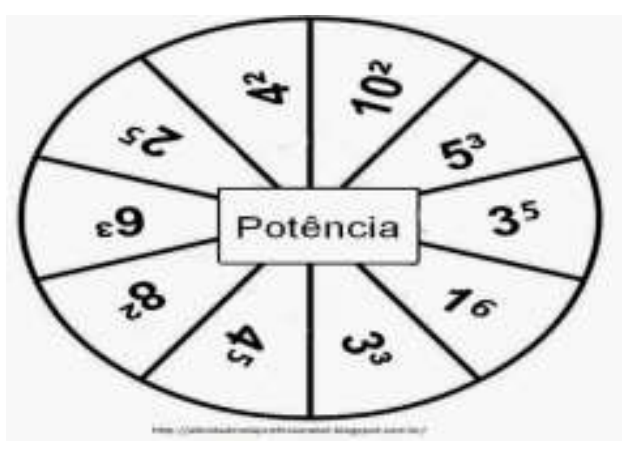

Figura 1

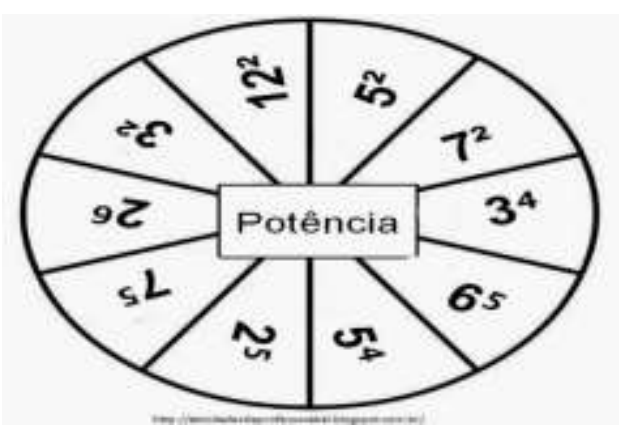

Figura 2

Educação, Psicologia e Interfaces, Volume 2, Número 3, p. 71-81, Setembro/Dezembro, 2018. ISSN: 2594-5343. DOI: https://doi.org/10.37444/issn-2594-5343.v2i3.75 


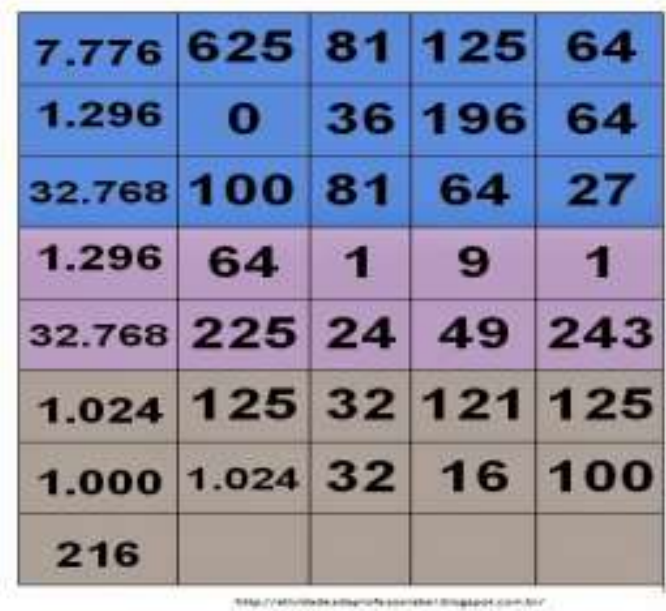

Figura 3

\begin{tabular}{|c|c|c|c|c|}
\hline 125 & 64 & 25 & 625 & 0 \\
\hline 225 & 49 & 49 & 144 & 64 \\
\hline 1000 & 32 & 1 & 25 & 1 \\
\hline 243 & 16 & 27 & 49 & 32 \\
\hline 125 & 100 & 32 & 81 & 49 \\
\hline 100 & 125 & 32 & 343 & 64 \\
\hline 243 & 64 & 64 & 64 & 32 \\
\hline 1.024 & 216 & 9 & 49 & 1 \\
\hline 16.807 & 625 & 0 & 169 & 4 \\
\hline
\end{tabular}

Figura 4

Na sequência foi explicado aos alunos as regras do jogo, que são: $1^{\mathrm{a}}$ juntos os jogadores resolverão as potências, encontrando os resultados; $2^{\mathrm{a}}$ depois devem procurar as respostas nos cartões e fixar com o clipe o resultado correspondente; $3^{\mathrm{a}}$ a dupla que terminar primeiro com as respostas corretas vence o jogo.

\section{RESULTADOS E DISCUSSÃO}

A educação matemática surgiu no século XIX, em consequência dos primeiros questionamentos sobre o ensino de matemática. A evolução do conceito de educação matemática mostra que os problemas de ensino, até meados da década de 70 , foram analisados utilizando apenas aspectos isolados de elementos que constituem o ensino, com isso a causa do fracasso no ensino de matemática, era procurada ora nos objetivos, ora nos métodos, ora nos conteúdos.

A matemática está presente na vida da maioria das pessoas de maneira direta ou indireta. Em quase todos os momentos do cotidiano, exercita-se os conhecimentos matemáticos. Apesar de ser utilizada praticamente em todas as áreas do conhecimento, nem sempre é fácil mostrar aos alunos, aplicações que despertem seu interesse ou que possam motivá-los através de problemas contextualizados.

A Matemática vem sofrendo nos últimos anos mudanças significativas quanto às questões voltadas ao processo de ensino e aprendizagem. Impulsionada pelas modificações na ciência, na tecnologia e nas metodologias de ensino que tratam sobre a cognição e as formas de aprendizagem, a matemática tradicional baseada na repetição e 
na reprovação abre espaço para novas metodologias e oportuniza ao professor de matemática, o uso de novas práticas na condução do processo de ensino.

Hoje a matemática vem passando por uma grande transformação. Isso é absolutamente natural. Os meios de observação, de coleção de dados e de processamento desses dados, que são essenciais na criação matemática, mudaram profundamente. Não que se tenha relaxado o rigor, mas, sem dúvida, o rigor científico hoje é de outra natureza (D’AMBROSIO, 2009, p. 58).

No ensino de matemática, já existe muitas possibilidades de trabalhar os conceitos desta disciplina, não utilizando o ensino tradicional, mas, levando em consideração outras propostas metodológicas, como a resolução de problemas, a abordagem Etnomatemática, o uso de computadores, a modelagem matemática e o uso de jogos matemáticos, procurando fazer com que o aluno deixe de ser um simples receptor de conteúdos, passando a interagir e participando do próprio processo de construção do conhecimento.

A análise de novos elementos incorporados ao ensino de matemática não pode deixar de considerar o avanço das discussões a respeito da educação e dos fatores que contribuem para uma melhor aprendizagem. Sendo assim, o jogo aparece dentro de um amplo cenário que procura apresentar a educação matemática, em bases cada vez mais cientificas.

Rêgo e Rêgo (2000) destacam que é premente a introdução de novas metodologias de ensino, onde o aluno seja sujeito da aprendizagem, respeitando-se o seu contexto e levando em consideração os aspectos recreativos e lúdicos das motivações próprias de sua idade, sua imensa curiosidade e desejo de realizar atividades em grupo.

\subsection{O JOGO E O DESENVOLVIMENTO COGNITIVO}

Atualmente tem-se atribuído grande relevância à utilização de brincadeiras e outros recursos lúdicos, que favoreçam e oportunizem o desenvolvimento psicomotor e cognitivo da criança de zero a cinco anos. O brincar constitui-se numa atividade educativa, assumindo um papel de intervenção e prática pedagógica, pois ao ser executada, desde que de maneira adequada, possibilita à criança criar circunstâncias importantes para seu desenvolvimento e para a sua aprendizagem.

Educação, Psicologia e Interfaces, Volume 2, Número 3, p. 71-81, Setembro/Dezembro, 2018.

ISSN: 2594-5343. DOI: https://doi.org/10.37444/issn-2594-5343.v2i3.75 
Nesta perspectiva, verifica-se o quanto é importante que a criança brinque, pois assim sustenta sua vida interior, desvendando sua aptidão e buscando um significado para a vida. Deste modo, a ausência de tempo e, principalmente de oportunidade para brincar, torna-se profundamente prejudicial ao desenvolvimento infantil.

O jogo propicia um ambiente favorável ao interesse da criança, não apenas pelos objetos que o constituem, mas também pelo desafio das regras impostas por uma situação imaginária que, por sua vez, pode ser considerada como um meio para o desenvolvimento do pensamento abstrato. É fundamental inserir as crianças em atividades que permitam um caminho que vai da imaginação à abstração, através de processos de levantamento de hipóteses e testagem de conjecturas, reflexão, análise, síntese e criação, pela criança, de estratégias diversificadas de resolução dos problemas em jogo. O processo de criação está diretamente relacionado à imaginação.

A utilização do lúdico na educação tem também, além do objetivo de desenvolver o aprendizado de forma mais atrativa para o aluno, o objetivo do resgate histórico-cultural dessas atividades. É um ótimo momento para o reconhecimento do seu histórico familiar e de sua cultura regional.

\section{2 O JOGO NO ENSINO DA MATEMÁTICA}

Os jogos, ultimamente, vêm ganhando espaço em nossas escolas numa tentativa de trazer o lúdico para dentro da sala de aula. A pretensão da maioria dos professores, com a sua utilização, é a de tornar as aulas mais agradáveis com o intuito de fazer com que a aprendizagem torne-se algo fascinante.

Além disso, as atividades lúdicas podem ser consideradas como uma estratégia que estimula o raciocínio levando o aluno a enfrentar situações conflitantes relacionadas com seu cotidiano e, também, a utilização dos jogos vem confirmar o valor formativo da matemática, não no sentido apenas de auxiliar na estruturação do pensamento e do raciocínio dedutivo, mas, também, de auxiliar na aquisição de atitudes.

Segundo Gardner (1961, p. XI), "pode-se dizer que os jogos matemáticos ou 'as matemáticas recreativas' são matemáticas - não importa de que tipo - carregado de um forte componente lúdico". Ao utilizar o lúdico para o ensino da matemática o professor está mediando o aprendizado dos alunos que pode efetivamente adquirir um conhecimento, proporcionando alterações em sua estrutura cognitiva. 
O importante é que os objetivos com o jogo estejam claros, a metodologia a ser utilizada seja adequada ao nível que se está trabalhando e, principalmente, que represente uma atividade desafiadora ao aluno para o desencadeamento do processo.

\section{4. OS JOGOS MATEMÁTICOS EM SALA DE AULA}

O jogo se convenientemente planejado, pode ser um recurso pedagógico eficaz para a construção do conhecimento matemático. Vygotsky afirmava que através do brinquedo a criança apreende a agir numa esfera cognitivista, sendo livre para determinar suas próprias ações. Segundo ele, o brinquedo estimula a curiosidade e a autoconfiança, proporcionando o desenvolvimento da linguagem, do pensamento, da concentração e da atenção.

O uso de jogos no ensino de matemática tem o objetivo de fazer com que os alunos gostem de apreender esta disciplina, mudando a rotina da classe e despertando o interesse do aluno envolvido. A aprendizagem através de jogos, como dominó, palavras cruzadas, jogos de tabuleiro, memória e outros, que permitam que o aluno faça da aprendizagem um processo interessante e até divertido. Para isso, os jogos devem ser utilizados ocasionalmente para sanar as lacunas que se produzem na atividade escolar diária. Nesse sentido, há três aspectos que por si só justificam a incorporação do jogo nas aulas: o caráter lúdico, o desenvolvimento das técnicas intelectuais e a formação de relações sociais.

Os jogos são educativos, sendo assim, requerem um plano de ação que permita a aprendizagem de conceitos matemáticos. Já que os jogos em sala de aula são importantes, devemos ocupar um horário dentro do nosso planejamento, de modo a permitir que o professor possa explorar todo o potencial dos jogos, processos de solução, registros e discussões sobre possíveis caminhos que poderão surgir.

Os jogos podem ser utilizados para introduzir, amadurecer conteúdos e preparar o aluno para aprofundar os conteúdos já trabalhados. Devem ser escolhidos e preparados com cuidado para levar o aluno a adquirir conceitos matemáticos importantes. Devemos utilizá-los não como instrumentos recreativos na aprendizagem, mas como facilitadores, colaborando para os bloqueios que os alunos apresentam em relação a alguns conteúdos matemáticos. Segundo (Malba Tahan, 1968) "para que os jogos produzam os efeitos

Educação, Psicologia e Interfaces, Volume 2, Número 3, p. 71-81, Setembro/Dezembro, 2018. 
desejados é preciso que sejam de certa forma, dirigidos pelos educadores". Partindo do princípio que as crianças pensam de maneira diferente dos adultos e que nosso objetivo não é ensiná-las a jogar, devemos acompanhar a maneira como as crianças jogam, sendo observadores atentos, interferindo para colocar questões interessantes, mas sem perturbar a dinâmica dos grupos, para a partir disso, auxiliá-las a construir regras e a pensar de modo que elas entendam.

Segundo Petty (1995, p.2) promover o desenvolvimento do raciocínio das crianças por meio de situações em que jogos de regras são instrumento para exercitar e estimular um pensar com lógica e critério, porque interpretar informações, buscar soluções, levantar hipóteses e coordenar diferentes pontos de vista são condições para jogar. Além disso, eles também fazem parte das condições para se aprender as disciplinas escolares. $\mathrm{O}$ trabalho com jogos matemáticos em sala de aula nos traz alguns benefícios:

- Conseguimos detectar os alunos que realmente estão com dificuldades de aprendizagem.

- O aluno demonstra para seus colegas e para o professor se o conteúdo foi bem assimilado.

- Pode existir uma competição entre os alunos, pois almejam vencer e por isso aperfeiçoam-se e buscam alcançar seus limites.

- Durante o desenrolar de um jogo, observamos que os alunos se tornam mais críticos, alertas e confiantes, expressando o que pensam, elaborando perguntas e tirando conclusões sem necessidade da interferência ou aprovação do professor.

- Não existe o medo de errar, pois o erro é considerado um degrau necessário para se chegar a uma resposta correta.

- Os alunos se empolgam com o clima de uma aula diferente, o que faz com que apreendam sem perceber.

Mas, devemos também, ter alguns cuidados ao escolher os jogos a serem utilizados:

- Não tornar o jogo algo obrigatório.

- Escolher jogos em que o fator sorte não interfira no resultado do jogo, permitindo que vença aquele que descobrir as melhores estratégias. 
- Utilizar atividades que envolvam dois ou mais alunos, para proporcionar a interação social.

- Estabelecer regras, que podem ou não serem modificadas no decorrer de um jogo.

- Trabalhar a frustração pela derrota na criança, no sentido de minimizá-la.

- Estudar o jogo antes de aplicá-lo aos alunos (o que só é possível jogando).

Para a aprendizagem, de acordo com o tipo de jogo, é necessário que a criança tenha um determinado nível de desenvolvimento, as situações de jogo são consideradas parte das atividades pedagógicas, justamente por serem elementos estimuladores do desenvolvimento. É esse raciocínio de que os alunos apreendem através de jogos que nos levará a utilizá-los em sala de aula.

Muito ouvimos falar que se deve vincular a teoria à prática, mas quase não o fazemos. Utilizar jogos como um recurso didático é uma chance que temos de fazê-lo. Eles podem ser usados em sala de aula como um prolongamento da prática habitual da aula, são recursos interessantes e eficientes, que podem auxiliar os alunos na compreensão dos conteúdos aplicados.

Na intenção de analisar a repercursão da utilização do jogo Roda da Potenciação, após a aplicação desse jogo e de observer posteriormente o desempenho que havia sido obtido pelos alunos com o auxílio do mesmo, era perceptível a sua colaboração.

O jogo Roda da Potenciação contribuiu para melhor entendimento e fixação do conteúdo que estava sendo abordado na classe, que no caso era de potência e radiciação, que de uma forma descontraída mas com objetivos firmados previamente pelos aplicadores, a aplicação pode possibilitar aos alunos o ensino da disciplina de maneira mais eficaz e contextualizada, além de promover um processo de socialização tanto do conhecimento, quanto das experiências adquiridas na prática do jogo e do convivio escolar, simultaneamente.

Fontana (1997) ressalta que, este tipo de jogo em sala de aula, ultrapassa o ensino dos conteúdos lúdicos, ou seja, as crianças nem percebem que estão aprendendo e essa pouca percepção induzida está totalmente relacionada a maneira que o jogo foi aplicado. Salienta ainda que o jogo não é o material exclusivo para a compreensão do conteúdo, ele

Educação, Psicologia e Interfaces, Volume 2, Número 3, p. 71-81, Setembro/Dezembro, 2018. 
teria a função de preencher as lacunas encontradas pelos os alunos para uma mais complete assimilação do mesmo.

\section{CONSIDERAÇÕES FINAIS}

O uso de jogos contribui para desenvolvimento do conhecimento matemático. A pesquisa bibliográfica e o relato de experiência demonstaram que as atividades lúdicas auxiliam no ensino de matemática. Observou-se nas atividades de monitoria que os alunos tinham dificuldades em entender e assimilar o conteúdo da forma tradicional, assim o uso do jogo foi relevante para a sua aprendiagem.

Percebe-se ainda que só o uso dos jogos não é suficiente para que o aluno aprenda e assimile o conteúdo de forma mais completa. Assim, é perceptível que o papel do professor deve buscar formas para melhorar o ensino da matemática, com recursos alternativos que possibilitem ao aluno obter bons resultados na disciplina, contribuindo ainda para uma formação pessoal do mesmo. Cabe situar que os alunos que participaram das atividades com os jogos, em sua maioria, necessitam desenvolver capacidades de natureza prática para lidar com a atividade matemática em sua vida diária. Quando essa capacidade é potencializada pela escola a aprendizagem apresenta melhor resultado.

Neste sentido, é fundamental a presença de um professor investigador, crítico e reflexivo que estude, pesquise e produza materiais didáticos, oportunizando a construção de conceitos matemáticos e oferecendo condições favoráveis para que os estudantes aprendam, apreciem e valorizem a Matemática. Para dar conta das demandas existentes em sala de aula, o professor deve buscar os conhecimentos necessários para uma melhor compreensão do processo ensino-aprendizagem, da educação e do papel da escola no mundo contemporâneo.

\section{REFERÊNCIAS BIBLIOGRÁFICAS}

D’ AMBRÓSIO, Ubiratan. Educação matemática: Da teoria à prática, $17^{\mathrm{a}}$ edição. Campinas, SP: Papirus, 2009.

FONTANA, R. Psicologia e trabalho pedagógico. São Paulo: Atual, 1997.

GARDNER, M. Divertimentos Matemáticos. Tradução Bruno Mazza. São Paulo: Ibrasa, 1961.

MOURA, , Manoel Oriosvaldo de. O jogo e a construção do conhecimento. São Paulo: FDE, n.10, p. 45-53, 1991.

Educação, Psicologia e Interfaces, Volume 2, Número 3, p. 71-81, Setembro/Dezembro, 2018. 
PETTY, A. L. S. Ensaio sobre o Valor Pedagógico dos Jogos de Regras: uma perspectiva construtivista. São Paulo, SP, 1995. 133p. Dissertação de Mestrado. Instituto de Psicologia, USP.

RÊGO, R.G.; RÊGO, R.M. Matemática ativa. João Pessoa: Universitária/UFPB, INEP, Comped: 2000.

TAHAN, Malba. O homem que calculava. Rio de Janeiro: Record, 1968.

\section{Credenciais da/os autora/es}

SANTOS, Paula. Universidade do Estado do Rio Grande do Norte (UERN) / Rio Grande do Norte - Brasil.

SILVA, Raiane. Universidade do Estado do Rio Grande do Norte (UERN) / Rio Grande do Norte - Brasil.

REIS, Caio. Universidade do Estado do Rio Grande do Norte (UERN) / Rio Grande do Norte - Brasil.

Endereço para correspondência: Paula Menezes dos Santos. Rua Marechal Deodoro - Bairro Centro, Areia Branca, Rio Grande do Norte, 59655-000, Brasil. E-mail: paulamenezescl@gmail.com

Como citar este artigo (Formato ABNT): SANTOS, Paula; SILVA, Raiane; REIS Caio. O uso do jogo no ensino da matemática. Educação, Psicologia e Interfaces, vol.2, n.3, p. 7181, 2018. DOI: https://doi.org/10.37444/issn-2594-5343.v2i3.75

Recebido: 04/02/2018.

Aceito: 26/05/2018. 